\title{
KÕRGHARITUKS TEISES KEELES
}

\section{Birute Klaas}

Ülevaade. Artiklis antakse ülevaade kõrgkooliõpingutele eelneva muukeelse kooli lõpetanud üliõpilastele mõeldud 80o-tunnise eesti keele ja kultuuri ettevalmistusprogrammi (nn eesti keele aasta) korraldamisest Eesti avalik-õiguslikes ülikoolides, keskendades peatähelepanu Tartu Ülikooli kogemusele antud valdkonnas. Jälgitakse ka aastase programmi lõpetanud üliõpilaste edenemist järgnevate aastate jooksul, nende edasijõudmist ülikoolis võrdlevalt teiste Eesti muukeelsete üldhariduskoolide lõpetanud üliõpilastega, kes on otse peale kooli lõpetamist asunud õppima erialateaduskondadesse. Artiklis analüüsitakse kvalitatiivselt õppejõudude ja muukeelsete üliõpilaste hoiakuid, motivatsiooni ja hinnanguid eesti keele aasta suhtes. Materjal on kogutud eesti keelt õpetavate keelekeskuse õppejõududega tehtud intervjuudest ja üliõpilastelt tagasiside korras saadud ainekursuste hindamise ankeetidest.

Võtmesõnad: teine keel, teise keele omandamine, kakskeelne haridus, keelepoliitika, hariduspoliitika, eesti keel

\section{Sissejuhatus}

2000/2001. õppeaastast alates on Haridus- ja Teadusministeeriumi määruse järgi Eesti avalik-õiguslikes kõrgkoolides õppekeeleks eesti keel. Kõigi muukeelsete koolide lõpetanud üliõpilastele, kes on riigikeele riigieksamil saanud alla $60 \%$ punktidest (eksam kontrollib kesktaseme saavutamist), on antud võimalus täiendavalt eesti keelt õppida. Selleks on nende õpingute nominaalaega pikendatud ühe aasta võrra ja kõrgkoolid pakuvad neile aastast eesti keele ja kultuuri alast intensiivõpet, mis peaks üliõpilased valmistama ette eestikeelseks õppetööks.

"Eesti keele arendamise strateegia 2004-2010" (EKAS) raames valminud eesti keele teise keelena / võõrkeelena seisundikirjelduses andsin ülevaate eesti keele ja kultuuri ettevalmistusprogrammi - nn eesti keele aasta - käivitumisest eesti avalik-õiguslikes kõrgkoolides ja ka muukeelsetele üliõpilastele pakutavast 
eesti keele õppest (vt ka Klaas 2004). Kirjeldus hõlmas nii Eesti muukeelsetest koolidest kõrgkoolidesse õppima asunuid kui ka välisüliõpilasi. Käesolev artikkel vaatleb muukeelsete eestlaste ${ }^{1}$ edenemist eestikeelses kõrgharidusruumis, kusjuures peatähelepanu on keskendatud TÜ kogemusele.

Jälgin aastase õppe läbinud üliõpilaste edenemist järgnevate aastate jooksul. Nende edasijõudmist ülikoolis on võrreldud teiste Eesti muukeelsete üliõpilastega, kes on erialateaduskondadesse õppima asunud otse peale muukeelse kooli lõpetamist, samuti eesti emakeelega üliõpilastega. Andmed on pärit TÜ õppeinfosüsteemist (ÕIS). ${ }^{2}$ Analüüsitud on õppejõudude ja muukeelsete üliõpilaste hoiakuid, motivatsiooni ja hinnanguid eesti keele aasta osas. Materjal on kogutud eesti keelt õpetavate keelekeskuse õppejõududega tehtud intervjuudest ja üliopilastelt tagasiside korras saadud ainekursuste hindamise ankeetidest.

\section{Eesti muukeelsete koolide Iópetanud TÜ-s}

Subjektiivse kogemuse põhjal võin väita, et TÜ õppehoonetes on viimastel aastatel üha rohkem kuulda vene keelt. Tabel 1 iseloomustab põhiõppesse vastuvõttu, näidates ära, kui suur on muukeelsete koolide lõpetanute protsent TÜ-sse õppima asunud noortest. Artikli kirjutamise ajaks ei olnud võimalik veel esitada arvandmeid 2005/2006. õ-a vastuvõtu kohta. Muukeelsetest gümnaasiumidest tulnud üliõpilasi nimetatakse siin ja edaspidi venekeelseteks ja nende hulk on viimase viie aasta jooksul olnud üsnagi stabiilne, kõikudes 17-18\% piirimail. Ilma Narva kolledžita, kelle peamine sihtgrupp ongi Ida-Virumaa muukeelsete koolide lõpetajad, on ülejäänud TÜ õppekavadel õppima asunud venekeelseid noori umbes $13 \%$.

Tabel 1. Vastuvõtt TÜ põhiõppesse

\begin{tabular}{|l|c|c|c|}
\hline Aasta & Eestikeelsed & Venekeelsed & Kokku \\
\hline 2000 & $82,55 \%$ & $17,45 \%$ & 2137 \\
\hline 2001 & $82,5 \%$ & $17,5 \%$ & 1999 \\
\hline 2002 & $83,16 \%$ & $16,84 \%$ & 2155 \\
\hline 2003 & $83,83 \%$ & $16,17 \%$ & 1991 \\
\hline 2004 & $81,77 \%$ & $18,23 \%$ & 2419 \\
\hline 2004 (õpib) & $82,17 \%$ & $17,83 \%$ & 2316 \\
\hline 2004 (v.a Narva kolledž) & $86,32 \%$ & $13,68 \%$ & 2201 \\
\hline 2003 (v.a Narva kolledž) & $87,1 \%$ & $12,9 \%$ & 1627 \\
\hline
\end{tabular}

Üliõpilased jagunevad rahastusallika osas riigieelarvelisteks ja riigieelarvevälisteks, st viimased peavad oma õpingud ise kinni maksma. Eesti ühiskonnas liigub müüt, et muukeelne noor ei ole konkurentsivõimeline, võistlemaks eesti noortega riigieelarveliste kohtade pärast. Tegelikult on jagunemine 2004. a TÜ-sse vastuvõetute hulgas üsna sarnane: riigieelarvelisel kohal õpib 67,5\% eestikeelsetest ja 70\% venekeelsetest noortest, oma raha eest siis vastavalt 32,5\% eestikeelseid ja $30 \%$ venekeelseid vastuvõetuid (andmed seisuga 15. märts 2005).

${ }^{1}$ Kasutan artiklis teadlikult nimetust muukeelne eestlane, kus eestlane tähistab Eesti riigi kodanikku ja mitte rahvust.

${ }^{2}$ Vt https://www.is.ut.ee/pls/ois/tere.tulemast (15.3.2006). Andmete esitamiskõlbulikuks töötlemise eest avaldan erilist tänu Enn Lasnale, TÜ õppeinfosüsteemi grupi spetsialistile. 
Mõnel erialal, nagu õigusteaduses (nii õigusteaduskonnas kui ka Tallinna õigusinstituudis), on oma raha eest õppijaid tunduvalt rohkem kui riigieelarvelisi üliõpilasi, aga seda nii venekeelsete kui ka eestikeelsete hulgas - juristi diplomi saamisesse on valmis investeerima mõlemad.

Kokku on igal aastal (andmed alates 1999-st) vastu võetud 300-400 venekeelset üliõpilast (tabel 2). 2004/2005. õ-a rakendati TÜ-s esimest korda lävendipõhist vastuvõttu, mis suurendas märgatavalt vastuvõetud üliõpilaste arvu füüsika-keemiateaduskonnas ja matemaatika-informaatikateaduskonnas. Kokku asus 2004. a õppima ligi 100 venekeelset üliõpilast rohkem kui eelnevail aastail. Muukeelsete koolide lõpetajaid on kõikides teaduskondades ja kolledžites, kõige rohkem arstiteaduskonnas (42,18\% õppekavast), Narva kolledžis (97\% õppekavast).

Tabel 2. Venekeelsete üliõpilaste vastuvõtt TÜ-sse (lisa-aastata)

\begin{tabular}{|l|c|c|c|c|c|c|}
\hline Eriala (teaduskond, kolledž) & $\mathbf{1 9 9 9}$ & $\mathbf{2 0 0 0}$ & $\mathbf{2 0 0 1}$ & $\mathbf{2 0 0 2}$ & $\mathbf{2 0 0 3}$ & $\mathbf{2 0 0 4}$ \\
\hline öigusteaduskond & 2 & 4 & 5 & 12 & 5 & 9 \\
\hline arstiteaduskond & 72 & 59 & 58 & 77 & 80 & 93 \\
\hline filosoofiateaduskond & 59 & 47 & 62 & 52 & 49 & 48 \\
\hline bioloogia-geograafiateaduskond & 18 & 25 & 16 & 20 & 15 & 16 \\
\hline füüsika-keemiateaduskond & 41 & 37 & 31 & 20 & 24 & 44 \\
\hline kehakultuuriteaduskond & 6 & 10 & 4 & 16 & 10 & 9 \\
\hline majandusteaduskond & 32 & 20 & 20 & 23 & 15 & 20 \\
\hline matemaatika-informaatikateaduskond & 32 & 23 & 24 & 24 & 30 & 53 \\
\hline sotsiaalteaduskond & 18 & 16 & 14 & 11 & 4 & 11 \\
\hline usuteaduskond & - & 1 & 1 & 1 & 1 & 1 \\
\hline haridusteaduskond & - & - & - & - & 3 & 3 \\
\hline Pärnu kolledž & 4 & 4 & 9 & 6 & 6 & 10 \\
\hline Narva kolledž & 64 & 78 & 88 & 64 & 55 & 98 \\
\hline Türi kolledž & - & 2 & - & 1 & - & - \\
\hline Õpetajate seminar & - & - & 14 & 6 & 3 & - \\
\hline Õigusinstituut & - & - & - & 10 & 3 & 7 \\
\hline Kokku & $\mathbf{3 4 8}$ & $\mathbf{3 2 6}$ & $\mathbf{3 4 6}$ & $\mathbf{3 4 6}$ & $\mathbf{3 0 3}$ & $\mathbf{4 2 5}$ \\
\hline
\end{tabular}

Vana õppekava järgse bakalaureuseõppe nominaalaeg oli 4 aastat. Seega pidid 2000. a oma õpinguid alustanud üliõpilased 2004. a lõpudiplomini jõudma. Et see nii ei olnud, seda näitab tabel 3 .

Tabel 3. Põhiõppe lõpetanud üliõpilased 1999-2004

\begin{tabular}{|l|c|c|}
\hline Keskhariduse keel & Immatrikuleeritud 1999 & Immatrikuleeritud 2000 \\
\hline eesti & $48,15 \%$ & $30 \%$ \\
\hline vene & $42,8 \%$ & $21,47 \%$ \\
\hline
\end{tabular}


Nominaalse õppimisaja ületavad nii eestlased kui venelased. Samas näitavad andmed, et nominaalaja jooksul lõpetab eestikeelsetest üliõpilastest 30\%, venekeelsetest ainult 21,47\%. Aasta varem on lõpetanute protsent veidi ühtlasem - 1999. a alustanud üliõpilastest sai 2004. a bakalaureusekraadi $48,15 \%$ ja venekeelsetest 42,8\%. Kas venekeelsete üliõpilaste aeglasema edenemise põhjusteks on kehvem keeleoskus või vajadus teha õpingutes vaheaeg, et käia tööl ja hankida õpinguteks raha, on väga raske öelda. Siiski võib üks põhjustest olla õppekeelega seonduvad raskused. Erialateaduskonda vastu võetud venekeelse üliõpilase jaoks on õppekavas ette nähtud väga vähe eesti keelt. Valikainena pakuvad erialast eesti keelt vaid arstiteaduskond ja majandusteaduskond. Ehk ka selles peitub üks põhjus, miks muukeelsel üliõpilasel kulub lõpudiplomini jõudmiseks reeglina rohkem aega.

\section{Venekeelne õpe avalik-õiguslikes ülikoolides}

Haridus-ja teadusministri määrus lubab teha õppekeele osas erandeid, kui kõrgkooli nõukogu peab seda vajalikuks. Kõrgkoolidest viivad TTÜ ja osaliselt ka TÜ Narva kolledž oma õppetööd läbi ka venekeelsetes rühmades, aga tegemist on pigem kakskeelsete õppekavadega. Eriala spetsiifikast lähtuvalt õpivad ka TÜ ja TLÜ vene ja slaavi filoloogid põhiliselt vene keeles, nii nagu inglise filoloogid inglise ja saksa filoloogid saksa keeles. TLÜ-s on ajakirjandust võimalik ka vene keeles.

Eesmärgipäraselt kakskeelsed õppekavad, nagu seda on näiteks Narva kolledžis, on Eesti tingimustes igati õigustatud. Kõrgkool, kus valmistatakse ette muukeelsete lasteaedade ja algklasside õpetajaid, ei saagi teisiti toimida, pakkudes erialaaineid vene ja üldaineid eesti keeles. Kui koolieelse pedagoogika õppekava läbinud üliõpilane soovib õpinguid jätkata magistritasemel, et saavutada näiteks lasteaia juhatajale esitatud pädevusnõuded, asub ta õppima ainult eesti keeles. Narva kolledž on teinud ära tänuväärse töö ja muutnud akadeemilist kultuuri oma õppeasutuses. Kui 2000. a oli veel kogu õppetöö kolledžis venekeelne, siis 2003. a õpetati juba 35\% ja 2005. a 50\% ainetest eesti keeles. Ka nõuab kolledž oma üliõpilastelt eesti keele tasemeeksamite sooritamist. TÜ-s muukeelsetele üliõpilastele selliseid nõudeid ei esitata, nt tulevase arsti puhul ei kontrolli keegi tema keeleoskuse taset. Kuna õppetöö toimub eesti keeles, eeldatakse, et spetsialist valdab stuudiumi järel eesti keelt nõutud määral.

TTÜ-s on erialasid, kus 1. ja 2. opppeaastal on õppetöö vene keeles (nt energeetika), 3. õppeaastal on õppetöö valdavalt eesti keeles. Eesti keele aastat (ametlikult) vajavaid üliõpilasi on järjest vähem ja need suunatakse vajadusel TTÜ Virumaa kolledžisse. Samas näitab seik, et TTÜ-s toimub mitmel erialal õppetöö paralleelselt ka venekeelsetes rühmades seda, et vaatamata eesti keele oskuse osas n-ö kõlblikuks tunnistamisele, ei suuda üliõpilased siiski eestikeelsest õppetööst osa võtta. Teistes avalik-õiguslikes kõrgkoolides on alates 2000/2001. õ-a õppekeeleks eesti keel. 


\section{Eesti keele aasta TÜ-s}

\section{1. Üldisest korraldusest}

2000/2001. õ-a oli esimene, kui rakendus Haridusministeeriumi eesti keele aasta määrus: pakkuda täiendavat eesti keele õpet kõigile muukeelsete koolide lõpetanud üliõpilastele, kes on saanud riigikeele riigieksamil alla 60\% punktidest. Kõrgkoolid pakkusid muukeelsetele üliõpilastele kahte erinevat võimalust:

- üheaastane eesti keele ja kultuuri kursus (40 ainepunkti), mis eelneb põhiõpingutele;

- eesti keele aasta (40 ainepunkti) läbitakse paralleelselt põhiõpingutega kahe aasta jooksul.

Enamik avalik-õiguslikke kõrgkoole kasutab esimest mudelit, kus eesti keele aasta läbitakse enne põhiõpet. Teist mudelit kasutas esimestel aastatel TTÜ, nüüd suunatakse eesti keele aastat vajavad üliõpilased TTÜ Virumaa kolledžisse.

TÜ-s korraldab õpetust keelekeskus. Eesti keele aasta põhiline eesmärk on tõsta keeleoskus sellisele tasemele, et üliõpilane saaks osa võtta erialasest eestikeelsest õppetööst. ${ }^{3}$ Kuigi tegeldakse nii retseptiivsete (lugemine, kuulamine) kui ka produktiivsete (kõnelemine, kirjutamine) osaoskuste arendamisega, on üliõpilastel esmajoones vajalik loengutest ja eestikeelsetest õppematerjalidest aru saada. Õppe hulka (80o tundi aastas) kuulub nädalas 20 tundi auditoorset tööd.

Andmed eesti keele aastat läbima asunud üliõpilaste kohta teaduskondade lõikes on toodud tabelis 4. Põhjus, miks üliõpilasi oli 2001. a oluliselt vähem kui

Tabel 4. Eesti keele aasta üliõpilased TÜ-s

\begin{tabular}{|l|c|c|c|c|c|c|}
\hline Eriala (teaduskond, kolledž) & $\mathbf{2 0 0 0}$ & $\mathbf{2 0 0 1}$ & $\mathbf{2 0 0 2}$ & $\mathbf{2 0 0 3}$ & $\mathbf{2 0 0 4}$ & Kokku \\
\hline Õigusteaduskond & - & - & - & - & - & - \\
\hline arstiteaduskond & 4 & 1 & 2 & - & - & 7 \\
\hline filosoofiateaduskond & 12 & 1 & - & 2 & - & 15 \\
\hline bioloogia-geograafiateaduskond & 1 & 2 & - & - & - & 3 \\
\hline füüsika-keemiateaduskond & 10 & - & - & 2 & 6 & 18 \\
\hline kehakultuuriteaduskond & 1 & - & 1 & - & - & 2 \\
\hline majandusteaduskond & - & - & - & - & - & - \\
\hline matemaatika-informaatikateaduskond & 1 & - & - & 2 & 4 & 7 \\
\hline sotsiaalteaduskond & 1 & - & - & - & - & 1 \\
\hline usuteaduskond & - & - & - & - & - & - \\
\hline haridusteaduskond & - & - & - & - & - & - \\
\hline Pärnu kolledž & - & - & - & - & - & - \\
\hline Narva kolledž & 17 & - & 14 & 12 & 6 & 49 \\
\hline Türi kolledž & - & - & - & - & - & - \\
\hline Õpetajate seminar & - & - & - & 1 & - & 1 \\
\hline Õigusinstituut & - & - & - & - & - & - \\
\hline Kokku & $\mathbf{4 7}$ & $\mathbf{4}$ & $\mathbf{1 7}$ & $\mathbf{1 9}$ & $\mathbf{1 6}$ & $\mathbf{1 0 3}$ \\
\hline
\end{tabular}

${ }^{3}$ Vt eesti keele aasta kohta TÜ õpilastele www.fl.ut.ee/90857 (15.3.2006). 
sellele eelneval ja järgneval aastal, on see, et sel õppeaastal otsustas TÜ nõukogu järgida ministri määrust n-ö täht-tähelt - riik (ja ülikool) võimaldab õpet, aga ei kohusta üliõpilasi seda läbima. Alates 2003/2004. õ-a on eesti keele aasta TÜ-s taas kohustuslik kõigile esimese aasta üliõpilastele, kes riigikeele eksamil on saanud alla $60 \%$ punktidest.

\subsection{Eesti keele aasta positiivsed küljed ja probleemid}

Arvandmetele lisaks huvitas autorit eesti keele õpetajate ja üliõpilaste suhtumine eesti keele aastasse, et välja selgitada pakutava õppetöö sisulised ja vormilised voorused ja puudused. Intervjuueerisin keelekeskuse õpetajaid Anne Jänest ja Eve Raestet. Üliõpilaste hinnangud ja hoiakud selgusid õpetamise ja ainekursuste hindamise ankeetidele saadud vastustest. Küsimustikud olid anonüümsed. ${ }^{4}$

Vastuvõetud üliõpilaste eesti keele oskuse tase on iga aastaga märgatavalt tõusnud. Õpetajate hinnangul tuleb väga häid õppureid just Ida-Virumaalt (Narvast ja Sillamäelt), kes paistavad silma oma motivatsiooni ja hea keeleoskusega. Üliõpilased hindavad väga positiivselt seda, et riik võimaldab neile lisa-aasta eesti keele õpinguteks, mingit ahistust ei tunta.

Üliõpilastelt saadud tagasiside ja õppejõududega tehtud intervjuud lubavad välja tuua eesti keele aasta positiivsed küljed. (Kursiivis on esitatud üliõpilaste tagasisideankeetidest nopitud näiteid.)

- Intensiivõppe vorm (20 tundi nädalas, keelekeskkonnas) - intensiivkursustel toimub omamoodi keelekümblus, peale selle on Tartu - erinevalt Ida-Virumaast - oma eestikeelse keskkonnaga sobiv taust, et tundides õpitut iga päev ka tegelikus elus järele proovida.

- Keele-ja kultuuriõoe koos - Meeldis see, et oli ka kultuuri õppimisega seotud (ekskursioonid). Aineprogramm näeb ette keeleõppele lisaks loenguid ja seminare eesti kultuurist, kultuuriloolisi ekskursioone ja muuseumikülastusi.

- Piisav ettevalmistus eestikeelseks õppetööks erialateaduskonnas - Kursus aitab mul ülikoolis õppida oma eriala. Kuigi eesti keele aastal tegeldakse tundides peamiselt üldkeelega, siis kodulektüüriks peavad üliõpilased lugema erialast eestikeelset kirjandust, mis aitab kaasa oskussõnavara omandamisele.

- Kedagi pole eksmatrikuleeritud - alates 2001. a pole edasijõudmatuse tõttu ühtegi üliõpilast eksmatrikuleeritud. Üliõpilaste eksmatrikuleerimine edasijõudmatuse tõttu ei pruugi olla andetuse või laiskuse tagajärg. Sageli on põhjused hoopis selles, et majanduslik olukord ei luba üliõpilasel täie pingega õppetööst osa võtta, vaid ta peab kooli kõrvalt ka töötama. Siiski on väga positiivne, et eesti keele aasta läbinud üliõpilasi pole viimastel aastatel TÜ-st eksmatrikuleeritud. Kuigi üliõpilased on oma õpinguid alustanud keeleliselt kehvemalt lähtepositsioonilt, on aasta intensiivõpinguid aidanud eesti keele oskust tõsta sellisele tasemele, mis lubab neil edukalt erialateaduskondades õppida.

- Eesti keele aastat vajab aina vähem üliõpilasi - 2004. a kasvas muukeelsete üliõpilaste arv TÜ-s oluliselt (2003. a astus TÜ-sse 303 ja

${ }^{4}$ Praeguse TÜ õppekorralduse järgi peab üliõpilane enne eksamit ja arvestust andma õppeinfosüsteemi kaudu tagasisidet kursusest osavõtu, õppetöö raskusastme, arusaadavuse jms kohta. 
2004. a 425 venekeelset üliõpilast, vt tabel 2), kuid eesti keele aastat vajavate üliõpilaste arv jäi umbes samaks. Vähemalt sisseastujate puhul on tajutav eesti keele oskuse taseme tõus, mis ei luba nõustuda kriitikaga muukeelsetes gümnaasiumides kehva eesti keele õpetuse osas. Kindlasti on hakanud tulemusi andma ka mitmesugused keelelaagrid jt integratsiooniprojektid. ${ }^{5}$

- Motiveeritud üliópilased - Mul on vaja teada eesti keelt, sest ma elan Eestis. Eesti keelt on mulle väga vaja. Et olla tulevikus hea spetsialist, ma pean hästi rääkima eesti keelt. Puudusin ainult sïs, kui olin haige. Eesti keel teeb mu tulevikus tööturul konkurentsivõimeliseks. Nii õppejõudude hinnangutest kui ka üliõpilaste vastustest võib välja lugeda, et muukeelne üliõpilane on reeglina väga motiveeritud ja sihikindel. Motivatsioon keeleõppes on aga peamine liikumapanev jõud.

- Hea õppetöö kvaliteet (head õppejõud, ainekava, õppevahendid jne) Programm on ideaalne - saame seda, mida meile on vaja. Minu eesmärk oli minimaalse ajaga saada maksimaalsed teadmised. Tundides arutasime huvitavaid teemasid ja vajalikke asju. Tunnid olid huvitavamad kui koolis. Head õppetöö kvaliteeti näitab üliõpilaste edasine edasijõudmine erialateaduskondades. Ka tagasisideküsitlustes on väga palju kiidetud häid õpetajaid, ainekava ja õppevahendeid.

- Turvaline keskkond ülikooliellu integreerumiseks - uued õppekavad on toonud TÜ-sse sellise loengutüübi nagu valdkonnaõpetus, mida peetakse n-ö suurtes voorudes, kus auditooriumis on 300-500 üliõpilast. Lävendipõhine vastuvõtt on kasvatanud esmakursuslaste hulka veelgi, mistõttu algul tunneb üliõpilane kindlasti puudust isiklikust kontaktist õppejõuga, kadudes sadade ja sadade üliõpilaste massi hulka. Nii on arusaadav, et eesti keele aasta üliõpilased hindavad isikustatud ja õppijakeskset lähenemist, seda, et õppetöö toimub väikeses õpperühmas, kus on võimalik arvestada iga õppija vajadusi. Üliõpilased rõhutavad tundides valitsevat meeldivat ja sooja õhkkonda ning sõbralikke suhteid õpetaja ja õpilaste vahel. Üliõpilased on keelekeskuses "turvalises ja koduses” keskkonnas. Siiski võib intervjuudest ja küsimustike vastustest välja lugeda teatavat hirmu järgnevate aastate ees: kas saadakse hakkama erialaloengutes, kas suudetakse eestikeelsetega võistelda, kas muukeelsesse üliõpilasse suhtutakse veidi leebemalt keeleoskust arvestades jne. Üldiselt valitseb teaduskondades mõistev suhtumine muukeelsetesse üliõpilastesse ja neil lubatakse alguses teha eksamitöid ka vene keeles. Erialaõpingute edenedes paraneb ka üliõpilaste keeleoskus ja nad ei vaja enam erikohtlemist.

Kõige positiivse kõrval on intervjuudes ja tagasisideküsitlustes välja toodud ka häirivaid ja negatiivseid tegureid.

- Õppeaja pikenemine - paratamatult tähendab eesti keele aasta seda, et planeeritud 3-aastase bakalaureusetasemeni või 5-aastase magistritasemeni jõutakse üks aasta hiljem. Riigieelarvelistele üliõpilastele toob see kaasa kindlasti vähem pingeid, sest ka seda lisa-aastat rahastab riik. Riigieelarvevälised üliõpilased peavad aga hankima raha veel üheks õppeaastaks.

\footnotetext{
${ }^{5}$ Vt lähemalt Mitte-eestlaste Integratsiooni Sihtasutuse koduleheküljelt www.meis.ee (15.3.2006).
} 
- Erialaõpingute edasilükkumine - üliõpilastele mõjub negatiivselt ka see, et soovitud erialani jõutakse alles aasta pärast.

- Vähene valdkondlik spetsialiseerumine - Vajan rohkem erialakeelt. Jätkan kindlasti järgmisel aastal erialakeele tundides. Kuigi õppejõud püüavad õppematerjalide valikul arvestada erinevate valdkondade üliõpilaste soovide ja vajadustega, on paratamatu, et erialase oskussõnavaraga tegeleb üliõpilane siiski põhiliselt vaid kodulugemiseks mõeldud tekstide kaudu.

- Õpperühma heterogeensus eesti keele taseme poolest - tegemist oli põhiliselt 2004/2005. õ-a probleemiga, kui TÜ-s lisandusid rühma ka venekeelsed välisüliõpilased, kelle eesti keele oskus oli olematu. 2005/ 2006. õ-a avati välisüliõpilaste jaoks eraldi rühm.

\section{Kokkuvõte}

Artiklis esitatu põhjal võib kokkuvõtvalt väita, et motiveeritud muukeelsed eestlased on võimelised kõrgkoolis edukalt eesti keeles õppima. Ka TÜ riigieelarvelistele kohtadele pääsenute protsent on sama eestikeelsetega võrreldes. Õppekava läbimises nominaalaja jooksul on küll erinevusi: eestikeelsed üliõpilased saavad diplomi nominaalaja lõpus mõnevõrra rohkem. Kas õpingute venimise peamine põhjus on keel või midagi muud, on esialgu raske öelda. Kindlasti aitaks üliõpilaste edenemisele aga kaasa täiendav eesti keele õpe erialaõpingute kõrval.

\section{Kirjandus, allikad}

EKAS = Eesti keele arendamise strateegia 2004-2010. Haridus- ja Teadusministeerium, Eesti Keelenõukogu. Tartu, 2004.

Klaas, Birute 2004. Eesti keel võõrkeelena ja eesti keel teise keelena Eesti kõrgkoolides. Emakeel ja teised keeled IV. Tartu ülikooli eesti keele (võõrkeelena) õppetooli toimetised 3. Tartu, 205-238.

Mitte-eestlaste Integratsiooni Sihtasutus. Internetis: www.meis.ee (15·3.2006).

TÜ keelekeskus. Internetis: http://www.fl.ut.ee/ke (15.3.2006).

ÕIS = Tartu ülikooli õppeinfosüsteem. Internetis: https://www.is.ut.ee/pls/ois/ tere.tulemast $(15 \cdot 3 \cdot 2006)$. 


\section{DELIVERING HIGHER EDUCATION IN A SECOND LANGUAGE}

\section{Birute Klaas}

The article provides an overview of the organization of the one-year Estonian Studies Programme at the Estonian public universities with a focus on the experience of the University of Tartu. The Estonian Studies Programme is an 8oo-hour preparatory course of the Estonian language and culture designed for the graduates of the Russian-medium schools in Estonia. The quantitative analysis concentrates on the attitudes, motivation, and evaluation of the lecturers and the nonnative students in regard to the Estonian Studies Programme. The research material comes from the interviews with the Estonian language lecturers of the language centres and the course evaluation questionnaires completed by the students. The analysis highlighted the following strengths of the Estonian Studies Programme: intensive studies in the language environment, combination of the language and culture studies, sufficient preparation to begin specialty studies at the faculty, since 2001 no students have been dismissed because of poor academic proficiency, the students are highly motivated, excellent teaching quality, and a safe environment that enables students to integrate into the university life, the number of students who have the need to participate in the Estonian Studies Programme is on the decline. Besides the obvious strengths, the following weaknesses could be observed: prolonged study period, postponement of specialty studies, poor specialization, heterogeneity of the study group in respect to the level of the Estonian language. The article concludes that the well-motivated non-Estonian students are able to study successfully in the Estonian language. The percentage of nonEstonian students admitted to the state-commissioned study places is similar compared to native speakers of Estonian. However, one can observe some differences in the completion of the curriculum within the nominal study period native Estonian speakers graduate sooner in comparison with non-Estonians. At present it is difficult to say whether the prolonged study period can be explained by poor language skills or some other factors. Additional Estonian studies during the specialty studies definitely result in the improved performance.

Keywords: second language, second language acquisition, bilingual education, language policy, education policy, Estonian

Birute Klaas (1957) on lõpetanud Tartu Ülikooli 1981. a eesti filoloogina. Kaitses

filoloogiakandidaadi väitekirja 1988 Tartu Ülikoolis, töötanud Tartu Ülikoolis alates 1987. Helsingi Ülikooli eesti keele lektor 1991-1995. Tartu Ülikooli keelekeskuse juhataja 1997-1999, eesti keele võõrkeelena korraline professor ja filosoofiateaduskonna dekaan 1999-2005, Eesti keelenõukogu esimees alates 2005, Tartu Ülikooli õppeprorektor alates 2006. On uurinud keeletüpoloogiat, läänemeresoome ja balti keelte vahelisi sarnasusi, väliseesti keelt, eesti keele võõrkeelena / teise keelena õpetamist, keelepoliitikat, hariduspoliitikat.

birute.klaas@ut.ee 